\title{
Investigation of Pool Workouts on Weight, Body Composition, Resting Energy Expenditure, and Quality of Life among Sedentary Obese Older Women
}

\author{
Mohammadreza Rezaeipour ${ }^{1}$ \\ Affiliations: 'University of Sistan and Baluchestan, Sport Sciences Department, Zahedan, Iran
}

Correspondence: M. Rezaeipour, University of Sistan and Baluchestan, Department of Sport Sciences, Postal Box: 98135-987, Postal Code: 9816745639, Zahedan, Iran. E-mail: rezaeipour@ped.usb.ac.ir

ABSTRACT The effects of water-based exercises on body composition continue to be controversial. The present study was proposed to assess the impact of pool workouts on weight, body composition, resting energy expenditure (REE), and the quality of life of sedentary obese older women without dietary intervention. Fifty-five sedentary obese women (mean age $69.5 \pm 4.3$ years) were selected in this prospective experimental study (2018). Participants were divided randomly into two groups: moderate-intensity continuous training (MICT) and high-intensity intermittent training (HIIT). Both pool workouts models included a similar energy expenditure ( $1500 \mathrm{kcal} /$ week), which were performed three times a week for 60 minutes each time and lasted for three months. The following measurements were carried out pre- and post-study: anthropometry, body composition, REE, and quality of life. The Wilcoxon nonparametric test was applied to compare between groups and times (pre- and post-study). The comparison of pre- and post-study showed significant decreases of body weight $(-0.7 \mathrm{~kg})$, BMI $\left(-0.5 \mathrm{~kg} / \mathrm{m}^{2}\right)$, fat mass (FM, $\left.-0.7 \mathrm{~kg}\right)$, and REE $(-81 \mathrm{kcal} /$ day) for the MICT ( $<<$ $0.05)$, and a significant decrease of the only FM $(-0.7 \mathrm{~kg})$ for the HIIT $(\mathrm{p}<0.05)$. Regarding the quality of life, decreased pain, social and vitality improvements were significant in the MICT group, but improved vitality and health status in the group of HIIT were significant. Pool workouts without the dietary control revealed a modest influence on the body composition of sedentary obese older women, with better results for MICT. However, the improvement in the quality of life cannot be ignored.

KEY WORDS aged, body composition, exercise, obesity, weight reduction programs, women

$@$ MJSSMontenegro

POOL WORKOUTS ON OLDER OBESE WOMEN

http://mjssm.me/?sekcija=article\&artid=194

\section{Introduction}

Several studies (Guillory et al., 2017; Rezaeipour \& Apanasenko, 2018) suggest that ageing is associated with obesity. There are many reasons for this, such as sarcopenia (Fielding, Vellas, Evans, Bhasin, Morley, et al., 2011). Poehlman et al. (2002) stated that physical exercise hinders the loss of fat-free tissue that usually occurs in certain situations of weight reduction and also can increase energy expenditure and cause weight loss. Pool workouts are a form of physical exercises that is widely recommended for various benefits for the health of those who practice them (Alves, Mota, Costa, \& Alves, 2004; Pöyhönen, Sipilä, Keskinen, Hautala, Savolainen, et al., 2002; Takeshima, Rogers, Watanabe, Brechue, Okada et al., 2002), and also because bodyweight is not a limiting factor to their practice, which lead to increased adherence to sports programmes (Pinto, Dias, Salvador, Figueira Júnior, \& Lima, 2008). The body loses about $90 \%$ of its weight when immersed to the shoulder in water (Kruel et al., 2005; Sova, 1998). In 1988, Sova suggested that pool workouts are particularly beneficial for persons with obesity who are at increased risk for the development of orthopaedic injury secondary to physical exercise; an exercise intensity kept at a lower level than recommended for the achievement of the improved cardiorespiratory resistance can be necessary.

Received: October 222019 | Accepted after revision: December 152019 | First published online: March 012020

(c) 2020 by the author(s). License MSA, Podgorica, Montenegro. This article is an open access article distributed under the terms and conditions of the Creative Commons Attribution (CC BY).

Conflict of interest: None declared. 
Aerobic exercise programs are known to contribute to weight loss and body fat without significant changes in muscle mass, while anaerobic exercises decrease fat mass and increase muscle mass, but have no significant impact on overall weight loss (Medicine, 2009). Therefore, characteristics of the prescribed exercises are essential as they apparently have a direct impact on the body composition of practitioners. Intermittent exercise, for example, seems to contribute to a loss of fat in comparison to continuous exercise, and this seems to be related to the increase in oxygen consumption after exercise (EPOC) and the oxidation of lipids, as a result of high-intensity exercise (Shiraev \& Barclay, 2012; Wallman, Plant, Rakimov, \& Maiorana, 2009). However, the aerobic and anaerobic effects of exercises on the body fat and muscle of the body continue to be controversial (Viana, Dantas, \& Perez, 2007).

There are few studies about the impacts of pool workouts on body composition and the health of obese older women. In addition, the existing studies vary greatly in terms of participants' time, age, goals, and model of exercises used, which makes it difficult to compare results. Therefore, the purpose of the study was to compare the effects of exercise-time-related models during pool workouts (traditional moderate-intensity continuous training (MICT) vs high-intensity intermittent training (HIIT)) on body composition, resting energy expenditure (REE), and quality of life among sedentary obese older women without dietary intervention.

\section{Methods}

Participants

The research complies with all relevant national statutes, institutional policies, and principles of the Helsinki Declaration. The Institutional Research Ethics Committee has approved informed consent forms and study protocol. All participants were informed about the study and, after obtaining a medical certificate that stated this study was not contraindicated, voluntarily provided written informed consent prior to enrollment. Fifty-five study participants were selected based on the following equation for 0.05 (error of $5 \%$ ), from sedentary obese older women between 65 to 75 years old (mean age $69.5 \pm 4.3$ years) who had taken part in the weight loss counselling program.

$$
n=\frac{z^{2} N p(1-p)}{\left(d^{2} N\right)+\left(z^{2} p[1-p]\right)}=\frac{1.96^{2} \times 64 \times 0.5 \times(1-0.5)}{\left(0.05^{2} \times 64\right)+\left(1.96^{2} \times 0.5 \times[1-0.5]\right)}=54.86
$$

This prospective experimental study was conducted at the Helal Sports Complex (Ferdos, 2018). The participants were randomly divided into two groups, including the high-intensity intermittent training program as a HIIT group, and the moderate-intensity continuous training program as a MICT group. Both programs lasted three months and consisted of three weekly sessions of 60 minutes each. The participants were evaluated at pre- and post-study. All activities were carried out in an indoor pool. Other criteria for inclusion were based on the following: weight stability over three-month $( \pm 2 \mathrm{~kg})$, blood pressures less than 140/85 mm Hg, body mass index (BMI) of more than $30 \mathrm{~kg} / \mathrm{m} 2$ and age over 65 years (Rezaeipour, 2014; Rezaeipour, 2018; Rezaeipour \& Apanasenko, 2018; Viana et al., 2007). Participants with diabetes mellitus, cardiovascular disease, smokers, infectious-contagious diseases, orthopaedic limitations, any medical contraindication to the water exercise, and who missed three consecutive sessions or more than one-third of the total sessions, were excluded (Rezaeipour, 2014; MR Rezaeipour, 2018; Rezaeipour \& Apanasenko, 2018; Viana et al., 2007).

\section{Pool workouts models}

The pool workout model for the HIT group was performed with intermittent movements of the upper (UL) and lower (LL) limbs. The exercise sessions for HIIT consisted of three phases: ten initial minutes of warming up using stretching movements, 40 minutes of a circuit program consisting of five standardized exercises in series (lasting two-minute each one with intermittent of two-minute between them and repeated three times) at $90-95 \%$ of maximum heart rate (HRmax), characterizing a vigorous-intensity according ACSM (Medicine, 2007), and ten final minutes of relaxation (cool-down). For the rest of the intervals, they had a light walk to the next station (to continue the exercise), and while waiting, they walked inside the pool (back and forth) to use active recovery. HR monitoring was measured by the formula of maximum heart rate $(H R \max )=220$ - age (years). Heart rate (HR) in the HIIT group was measured immediately after each exercise session. The pool workout program for the MICT group was performed without a break and with continuous movements of UL and LL. The sessions also included three phases: ten initial minutes of warming up by stretching exercises, 40 minutes of pool workouts involving the large muscle groups of UL and LL, and ten final minutes of relaxation (cooldown). The exercises were performed at 70-85\% HRmax, characterizing moderate to vigorous-intensity according to ACSM (Medicine, 2007). HR was monitored in the MICT group by being measured three times during and after the session.

Activities used during pool training are shown in Table 1. Plastic dumbbells and foam "noodles" were sports tools for both pool workouts models. Energy expenditure in both groups was the same (1500 kcal 
TABLE 1. Exercise Activities Used During the Pool Training

\begin{tabular}{ll}
\multicolumn{1}{c}{ Stages } & \multicolumn{1}{c}{ Exercise type } \\
\hline Warming up & Walk - 10 laps in the swimming pool \\
& $\begin{array}{l}\text { 1- Endurance activities(dancing and walking or both combined); } \\
\text { 2- Resistance activities (upper limbs: biceps curl, chest press, and lumbar rotation; } \\
\text { lower limbs: leg abduction and adduction, knee flexion and extension, leg curl and leg } \\
\text { press, and press of the calf) }\end{array}$ \\
Cool down / Relaxation & Stretching arms and legs and slow walking \\
\hline
\end{tabular}

per week), which has been converted into minutes per week, and the duration of the weekly exercises was adjusted accordingly.

\section{Measurements}

BMI was computed by dividing weight $(\mathrm{kg})$ by height $(\mathrm{m})$ squared, and the participants were classified according to the cut-off points recommended by the World Health Organization (WHO, 2000). Body weight was measured with light clothing and no shoes using a Scale-Tronix model 5002 (Wheaton, IL, USA) with a precision of $0.1 \mathrm{~kg}$. Height was computed with a stadiometer with $0.5 \mathrm{~cm}$ graduations and a maximum capacity of 2.0 m (Rezaeipour, 2014; Rezaeipour, Apanasenko, \& Nychyporuk, 2014). Both measures were implemented in duplicate and averaged.

Body composition analysis was evaluated using a tetrapolar bioelectrical impedance analyser (BIA 310A, Biodynamics, USA) according to a standardized manner. Fat-free mass (FFM) was estimated utilizing the tetrapolar resistance and reactance. Participants of the study were obese women; therefore, the following equation was utilized to calculate FFM and fat mass (FM) for obese women (Segal, Van Loan, Fitzgerald, Hodgdon, \& Van Itallie, 1988):

FFM $($ woman $)=0.00091186$ (height $) 2-0.01466 \times($ resistance at $50 \mathrm{~Hz})+0.29990$ (bodyweight $)-$ 0.07012 (Wagenmakers, Coakley, \& EDWARDS) + 9.37938; FM $(\mathrm{kg})=\mathrm{W}-\mathrm{FFM}$.

(FFM mass in kg; height in cm; resistance in ohms; body weight in Kg; age in full years)

Measurements of carbon dioxide production (VCO2) and oxygen consumption (VO2) were determined by indirect calorimetry (IC) via a Sensor Medics Calorimeter Vmax $29^{\circ}$ instrument (Sensor Medics Corporation, Yorba Linda - CA, USA). These gases were then included in Weir's formula (Weir, 1949) for the calculation of REE. Quality of life was evaluated through the SF-36 Quality of Life questionnaire that evaluates physical aspects, functional capacity, pain, mental health, emotional aspects, social aspects, vitality, and general health status (Campolina \& Ciconelli, 2008; Lima, Barros, César, Goldbaum, Carandina, et al., 2009).

\section{Method management}

Both groups were trained (three sessions) to adapt to water before the study. Alterations in leisure-time physical activity or energy consumption are associated with potentially conflicting research implications. Therefore, Participants were asked to complete diary records for four days (three weekdays and a weekend day) prior the starting the study and the same procedure was performed just after the intervention to report their leisure-time physical activity and nutrition habits throughout the study (Rezaeipour, 2014; Rezaeipour et al., 2014).

\section{Statistical analysis}

Normality distribution of data was not confirmed using the test of Kolmogorov-Smirnov. The Wilcoxon test was used for group and time point (pre- and post) comparisons. Data are reported as means and standard deviations $( \pm \mathrm{SD})$. The $\mathrm{p}<0.05$ was set as a significance level. All analyses were performed with the software of SPSS ver. 21.0 (for Windows).

\section{Results}

Fifty-five participants were selected at the preliminary phase of the study, 28 in the MICT group and 27 in the HIIT group. Loss of motivation and dissatisfaction with randomization were reasons for the elimination of seven participants (4 in MICT and 3 in HIIT), with 48 individuals completing the study (MICT: 24 and HIIT: 24). The variables studied at baseline have no significant differences between groups, and the groups were similar in all quality aspects of life $(\mathrm{p}>0.05)$.

As shown in Table 2, the assessment of the outcomes within each group regarding time points (pre- and post-study) revealed modest but significant reductions of weight, BMI, and FM for the MICT group ( $\mathrm{p}<$ 0.05). Furthermore, REE decreased significantly in the MICT group $(\mathrm{p}<0.05)$, while slightly increased in the HIIT group $(\mathrm{p}>0.05)$. In the HIIT group, only a significant decrease was observed in FM ( $<<$ $0.05)$. 
TABLE 2. Mean Comparison of Evaluated Parameters in Both Groups at Pre- and Post-study

\begin{tabular}{|c|c|c|c|c|c|c|}
\hline \multirow{2}{*}{ Variables } & \multicolumn{2}{|c|}{ MICT group $(n=24)$} & \multirow{2}{*}{ Mean variation } & \multicolumn{2}{|c|}{ HIIT group ( $n=24$ ) } & \multirow{2}{*}{ Mean variation } \\
\hline & Before & After & & Before & After & \\
\hline Weight, kg & $86.5(15.6)$ & $85.8(16.1)$ & $-0.7^{*}$ & $85.6(16.4)$ & $85.5(15.3)$ & -0.1 \\
\hline $\mathrm{BMI}, \mathrm{kg} / \mathrm{m}^{2}$ & $35.1(5.8)$ & $34.6(6.1)$ & $-0.5^{*}$ & $32.6(5.6)$ & $32.5(5.9)$ & -0.1 \\
\hline $\mathrm{FM}, \mathrm{kg}$ & $40.3(13.1)$ & $39.6(12.1)$ & $-0.7^{*}$ & $38.9(25.4)$ & $38.2(27.5)$ & $-0.7^{*}$ \\
\hline FFM, kg & $45.8(8.1)$ & $45.7(7.5)$ & -0.1 & $46.4(7.2)$ & $46.9(7.3)$ & +0.5 \\
\hline REE, kcal/day & $1459.1(176.2)$ & $1378.1(158.3)$ & $-81.0^{*}$ & $1466.9(229.7)$ & $1491.1(151.5)$ & +24.2 \\
\hline
\end{tabular}

Note. Data are reported as mean $( \pm$ SD), MICT: moderate-intensity continuous training, HIIT: high-intensity intermittent training, FM: fat mass, FFM: fat-free mass, REE: resting energy expenditure, ${ }^{*} p<0.05$.

A comparison of pre and post-study results have identified the improvement of vitality and social aspects and worsening of pain in the MICT as well as improved vitality and health status in the group of HIIT (Table 3).

As reported in Table 2, no differences between the groups were found in any of the assessed items in the poststudy phase $(\mathrm{p}>0.05)$.

TABLE 3. Evolution of Quality of Life Variables in MICT and HIIT Groups During the Study

\begin{tabular}{|c|c|c|c|c|c|c|}
\hline \multirow{2}{*}{ SF-36 Variables } & \multicolumn{2}{|c|}{ MICT group $(n=24)$} & \multirow{2}{*}{ Mean variation } & \multicolumn{2}{|c|}{ HIIT group ( $n=24)$} & \multirow{2}{*}{ Mean variation } \\
\hline & Before & After & & Before & After & \\
\hline Physical aspect & $73.6(35.9)$ & $86.6(14.5)$ & +13.0 & $81.0(21.1)$ & $82.6(21.8)$ & +1.6 \\
\hline Functional capacity & $64.8(19.1)$ & $78.8(15.6)$ & +14.0 & $66.0(14.3)$ & $72.1(24.7)$ & +6.1 \\
\hline Pain & $54.0(19.3)$ & $73.1(15.0)$ & $+19.1^{*}$ & $70.2(17.1)$ & $63.4(27.8)$ & -6.8 \\
\hline Mental health & $55.5(18.9)$ & $66.8(17.76)$ & +11.3 & $60.0(17.1)$ & $66.5(17.4)$ & +6.5 \\
\hline Emotional aspects & $58.1(28.9)$ & $58.9(26.8)$ & +0.8 & $68.7(14.3)$ & $55.6(32.1)$ & -13.1 \\
\hline Social aspects & $61.9(29.5)$ & $79.4(19.3)$ & $+17.5^{*}$ & $67.3(27.1)$ & $67.4(23.8)$ & +0.1 \\
\hline Vitality & $46.1(18.3)$ & $67.6(13.5)$ & $+21.5^{*}$ & $50.3(16.5)$ & $63.4(17.3)$ & $+13.1^{*}$ \\
\hline Health status & $68.0(17.1)$ & $73.5(16.5)$ & +5.5 & $63.4(17.5)$ & 76.7 (16.9) & $+13.3^{*}$ \\
\hline
\end{tabular}

Note. Data are reported as mean ( \pm SD), MICT: moderate-intensity continuous training, HIIT: high-intensity intermittent training, ${ }^{*} \mathrm{p}<0.05$.

\section{Discussion}

Current results showed that exercise-time-related models during pool workouts (intermittent vs continuous) are ineffective in terms of weight loss, changes in body composition, or changes in energy expenditure in sedentary obese older women. Pool workouts with continuous exercise have shown a slight advantage by providing some improvements in items related to the quality of life. Modest but significant weight loss, observed only in women of the MICT group, demonstrates that, in this case, a continuous pool workout had a more active role in weight loss than an intermittent pool workout. However, both groups reached a similar and significant loss of fat mass. Based on several studies (Rezaeipour, 2014; Rezaeipour et al., 2014), changes in body weight and composition in the state of exercise take at least three months, so the study was completed in three months.

In one previous study of ground-based exercise (Rezaeipour \& Apanasenko, 2018), more positive results on weight and body composition were achieved in women throughout the 12-week study of continuous and intermittent exercise, although the study included the category of middle age and was linked to an energy-restricted diet. However, measuring body composition by Louzada (2007) in women with obesity after an exercise program longer than the current (four-month), which were included walks and weight training within 30 minutes twice a week, has also not revealed significant differences in weight.

Gubiani, Pires Neto, Petroski, and Lopes (2001) stated that even aqua aerobics programs with a duration of eight-month and moderate intensity of $75 \%$ of HRmax cause significant, although modest, loss of body weight and composition, especially considering the duration. A review and meta-analysis of research (Garrow \& Summerbell, 1995; Wing, 1999) suggest similar outcomes: despite the benefits, the impact of exercise on body weight is modest, especially when exercise has nothing to do with an energy-restricted diet. In the study by Pöyhönen et al. (2002), the advantages of pool workouts are connected with the physical properties 
of water, with emphasis on resistance to advance, which is directly connected with the movement velocity. Therefore, it can be used as an alternative form of physical conditioning, taking benefits of the buoyancy of the water as an impact reducer (Kruel et al., 2005). It must also be noted that even when doing exercises in water, obese individuals have restrictions in mobility and difficulties in overcoming the resistance of water. Therefore, the intensity and activity velocity can be insufficient to generate greater influence on the studied variables, as both are directly connected with the exercise results. Another factor that may have contributed to the slight changes observed in the current study was the program duration and the isolated utilization of exercises for losing weight, not associated with food control. Both factors may have been limiting the effectiveness of pool workouts models. The lack of significant differences in three-month weight loss between the studied groups may be a reflection of the fact that water exercises do not have the effectiveness of the exercises on the ground or exercise with an energy restriction diet. Thus, the outcomes of this study are not consistent with the findings of Rezaeipour (2018) and Rezaeipour et al. (2018), who studied exercise-time-related models on the ground.

According to measured parameters of quality of life, a significant improvement of social and vitality aspects in MICT and vitality and health in HIIT was observed. Several studies (Anish, 2005; Wagenmakers et al., 1988) suggest that these improvements are related to increased synthesis of endorphins in the body of people who regularly exercise. Regular aerobic exercises have a positive impact on psychological and emotional disorders such as anxiety and depression, and also cognitive aspects (memory and learning), quality of life improvement and therefore are considered important therapeutic allies in treatment of these disorders (Anish, 2005; Antunes, Stella, Santos, Bueno, \& Mello, 2005).

The selection of older women made it impossible to generalize the results of the study. Other legal restrictions, such as potential bias and multiple analyses, were not found, except for the lack of commitment of some individuals who excluded from the study. This study is also suggested for men.

In conclusion, the research outcomes show that pool workouts models without an energy restriction have the same effect on FM. At the same time, the best results in terms of body weight are obtained with a model with the MICT feature. The social and health improvements have observed in these two programmes highlights the significant benefits of pool workouts for quality of life. These findings can be used clinically.

\section{References}

Alves, R. V., Mota, J., Costa, M. d. C., \& Alves, J. G. B. (2004). Physical fitness and elderly health effects of hydrogymnastics. Revista Brasileira de Medicina do Esporte, 10(1), 31-37. doi: 10.1590/S151786922004000100003

Anish, E. J. (2005). Exercise and its effects on the central nervous system. Current sports medicine reports, 4(1), 18-23. doi: 10.1097/01.CSMR.0000306066.14026.77

Antunes, H. K. M., Stella, S. G., Santos, R. F., Bueno, O. F. A., \& Mello, M. T. d. (2005). Depression, anxiety, and quality of life scores in seniors after an endurance exercise program. Brazilian Journal of Psychiatry, 27(4), 266-271. doi: 10.1590/S1516-44462005000400003

Campolina, A. G., \& Ciconelli, R. M. (2008). SF-36 and the development of new assessment tools for quality of life. Acta reumatologica Portuguesa, 33(2), 127-133.

Fielding, R. A., Vellas, B., Evans, W. J., Bhasin, S., Morley, J. E., Newman, A. B., et al. (2011). Sarcopenia: an undiagnosed condition in older adults. Current consensus definition: prevalence, etiology, and consequences. International working group on sarcopenia. Journal of the American Medical Directors Association, 12(4), 249-256. doi: 10.1016/j.jamda.2011.01.003

Garrow, J., \& Summerbell, C. (1995). Meta-analysis: effect of exercise, with or without dieting, on the body composition of overweight subjects. European journal of clinical nutrition, 49(1), 1-10. doi: 10.1038/ sj.ejcn. 1600534

Gubiani, G. L., Pires Neto, C. S., Petroski, É. L., \& Lopes, A. d. S. (2001). Efeitos da hidroginástica sobre indicadores antropométricos de mulheres entre 60 e 80 anos de idade. Rev. bras. cineantropom. desempenho hum, 3(1).

Guillory, B., Chen, J. a., Patel, S., Luo, J., Splenser, A., A., Mody, A., Ding, M., Baghaie, S., Anderson, B., Iankova, Blaga. (2017). Deletion of ghrelin prevents aging-associated obesity and muscle dysfunction without affecting longevity. Aging cell, 16(4), 859-869. doi: 10.1111/acel.12618

Kruel, L. F. M., Barella, R., Graef, F., Brentano, M. A., Figueiredo, P., Cardoso, A., et al. (2005). Efeitos de um treinamento de força aplicado em mulheres praticantes de hidroginástica. Revista Brasileira de Fisiologia do Exercício, 4(1), 32-38.

Lima, M. G., Barros, M. B. d. A., César, C. L. G., Goldbaum, M., Carandina, L., \& Ciconelli, R. M. (2009). Health-related quality of life among the elderly: a population-based study using the SF-36 survey. Cadernos de Saude Publica, 25(10), 2159-2167. doi: 10.1590/S0102-311X2009001000007

Louzada, E. (2007). Alterações em alguns aspectos da composição corporal em mulheres obesas após um programa de exercício físico. Master's thesis in Physical Education-Universidade São Judas Tadeu: São Paulo.

Medicine, A. C. o. S. (2007). Diretrizes de ACSM para os testes de esforço e sua prescrição: Guanabara Koogan.

Medicine, A. C. o. S. (2009). American College of Sports Medicine position stand. Progression models in resistance training for healthy adults. Medicine and science in sports and exercise, 41(3), 687. doi: 10.1249/ 
MSS.0b013e3181915670

Pinto, L. G., Dias, R. M. R., Salvador, E. P., Figueira Júnior, A., \& Lima, C. V. G. (2008). Efeito da utilização de bandas elásticas durante aulas de hidroginástica na força muscular de mulheres. Rev. bras. med. esporte, 14(5), 450-453. doi: 10.1590/S1517-86922008000500010

Poehlman, E. T., Denino, W. F., Beckett, T., Kinaman, K. A., Dionne, I. J., Dvorak, R., et al. (2002). Effects of endurance and resistance training on total daily energy expenditure in young women: a controlled randomized trial. The Journal of Clinical Endocrinology \& Metabolism, 87(3), 1004-1009. doi: 10.1210/ jcem.87.3.8282

Pöyhönen, T., Sipilä, S., Keskinen, K. L., Hautala, A., Savolainen, J., \& Mälkiä, E. (2002). Effects of aquatic resistance training on neuromuscular performance in healthy women. Medicine \& Science in Sports \& Exercise, 34(12), 2103-2109. doi: 10.1097/00005768-200212000-00036

Rezaeipour, M. (2014). Comparison of Two Types of Diets on Losing Weight and Lipid Profile of Overweight/Obese Middle-Aged Women Under Exercise Condition. Health Scope, 3(3). doi: 10.17795/ jhealthscope-15611

Rezaeipour, M. (2018). Study of exercise time models on weight loss and coronary risk panel in inactive middle-aged men by overweight or obesity. The Journal of Urmia University of Medical Sciences, 29(5), 389-397.

Rezaeipour, M., \& Apanasenko, G. L. (2018). Efficacy of Exercise Time Models in Weight-Loss and Coronary Risk Panel of Middle-Aged Females. Hormozgan Medical Journal, 22(3), e86318. doi: 10.5812/hmj.86318

Rezaeipour, M., Apanasenko, G. L., \& Nychyporuk, V. I. (2014). Investigating the effects of negative-calorie diet compared with low-calorie diet under exercise conditions on weight loss and lipid profile in overweight/obese middle-aged and older men. Turkish journal of medical sciences, 44(5), 792-798. doi: $10.3906 /$ sag-1303-10

Segal, K., Van Loan, M., Fitzgerald, P., Hodgdon, J., \& Van Itallie, T. B. (1988). Lean body mass estimation by bioelectrical impedance analysis: a four-site cross-validation study. The American journal of clinical nutrition, 47(1), 7-14. doi: 10.1093/ajcn/47.1.7

Shiraev, T., \& Barclay, G. (2012). Evidence-based exercise: Clinical benefits of high-intensity interval training. Australian family physician, 41(12), 960.

Sova, R. (1998). Hidroginástica na terceira idade, trad. Ana Maria Cardoso da Silva. In: São Paulo, ed. Manole Ltda.

Takeshima, N., Rogers, M. E., Watanabe, E., Brechue, W. F., Okada, A., Yamada, T., et al. (2002). Waterbased exercise improves health-related aspects of fitness in older women. Medicine \& Science in Sports \& Exercise, 34(3), 544-551. doi: 10.1097/00005768-200203000-00024

Viana, M. V., Dantas, E. H. M., \& Perez, A. J. (2007). Effects of a program of physical exercise competitors on muscle mass, aerobic power and corporal composition in adults aerobic and anaerobic. Fitness \& Performance Journal (Online Edition), 6(3). doi: 10.3900/fpj.6.3.135.e

Wagenmakers, A. J., Coakley, J. H., \& EDWARDS, R. H. (1988). The metabolic consequences of reduced habitual activities in patients with muscle pain and disease. Ergonomics, 31(11), 1519-1527. doi: $10.1080 / 00140138808966801$

Wallman, K., Plant, L. A., Rakimov, B., \& Maiorana, A. J. (2009). The effects of two modes of exercise on aerobic fitness and fat mass in an overweight population. Research in Sports Medicine, 17(3), 156-170. doi: $10.1080 / 15438620903120215$

Weir, J. d. V. (1949). New methods for calculating the metabolic rate with special reference to protein metabolism. The Journal of Physiology, 109(1-2), 1-9. doi: 10.1113/jphysiol.1949.sp004363

Wing, R. R. (1999). Physical activity in the treatment of the adulthood overweight and obesity: current evidence and research issues. Medicine and science in sports and exercise, 31(11 Suppl), S547-552. doi: 10.1097/00005768-199911001-00010

World, HO. (2000). Obesity: preventing and managing the global epidemic: the World Health Organization. 